\title{
Assessing the Value of Forest Landscapes: A Choice Experiment Approach
}

\author{
${ }^{1}$ Guy Garrod; Eric Ruto and Pat Snowdon
}

\begin{abstract}
Landscape planning and design occupies a major role in forest policy in the UK. Since the 1980s, UK forests have been managed increasingly for multi-purpose objectives, a policy which has been underpinned by international agreements on sustainable forestry. Within this context, there is a need to understand public preferences for forest landscapes in designing policies that meet the needs of multi-purpose forestry. This paper is based on a study to investigate public willingness to pay (WTP) for regular visual and recreational access to a wide variety of generic forest landscapes. A total of 33 forest landscapes were investigated, each of which was defined as a combination of the configuration of the planting and the landscape factors. Computer-generated images of each of these landscapes were used to underpin a series of choice experiments conducted as part of a questionnaire survey of over 400 households across Great Britain. The results confirm the importance of landscape in contributing to the social and environmental benefits provided by forests and suggests that current policies of woodland expansion may generate additional benefits especially if more woodland is located close to urban populations. The paper concludes by discussing the implications of these results for forest policy across the UK.

Keywords: Forest policy, environmental valuation, landscape, computer-generated images, choice experiments
\end{abstract}

\footnotetext{
1 Guy Garrod is Reader in Environmental Economics, School of Agriculture, Food and Rural Development, Newcastle University, UK; Eric Ruto is Lecturer, School of Agriculture, Food and Rural Development, Newcastle University, UK; Pat Snowdon is Economist, Forestry Commission, Edinburgh.
} 


\section{INTRODUCTION}

Multi-purpose forests provide benefits to a variety of user groups. Perhaps the most obvious beneficiaries are those individuals who enjoy recreational activities either in or adjacent to woodlands. These may be visitors to the area or local residents. In the case of the latter, benefits may also accrue from the aesthetic pleasure gained from regularly viewing the forest landscape. Commuters and other travellers may also benefit from the forest landscapes encountered on their journeys. Again, these benefits may arise from recreation or from enjoying views of the forest landscape.

This paper reports on a study funded by the Forestry Commission (FC) in the UK to investigate the benefits that individuals gain from forest views. Specifically, it examines forest landscape benefits derived by individuals who enjoy forest views from home and by those who encounter forests during their regular journeys. To ensure that amenity benefits are measured separately, recreational benefits are also investigated across these groups.

The main aim of the study was to devise and implement a methodology to allow public preferences for regular visual and recreational access to a wide variety of generic forest landscapes to be investigated. Achieving this aim would generate estimates of public willingness to pay (WTP) for different forest landscapes which could be used to inform forest planning decisions.

The paper is organised as follows. First, the literature on landscape benefits of forestry is reviewed. Second, the methodology and results of the study are presented. Finally, the policy implications of the study are discussed and conclusions drawn.

\section{EVALUATING LANDSCAPE BENEFITS}

The evaluation of agricultural and forest landscapes has traditionally been a concern of planners (e.g. Angileri and Toccolini, 1993) and system modellers (e.g. Anderson, 1981; Elefthriaids and Tsalikidis, 1990; Holgen and Lind, 1995). Other studies have investigated user preferences and attitudes towards woodlands and forests (e.g. Jorgensen and Anthopoulou, 2007; Burgess, 1995; Schroeder and Orland, 1994). In recent years UK agencies with an interest in landscape evaluation have developed systematic guidance for landscape character assessment (LCA) as a tool to assist management and planning (e.g. Cobham Resource Consultants, 1993; Swanwick, 2002). Since then LCA has been recommended in several UK Government Planning Policy Statements (e.g. PPS7: Sustainable Development in Rural Areas, Office of the Deputy Prime Minister, 2004) as an important tool to inform planning and development decisions. The importance of LCA and other methods of evaluating landscape quality have been emphasised by the UK becoming a signatory to the European Landscape Convention (ELC) in 2006. Among other things the ELC highlights the need to develop landscape policies dedicated to the protection, management and creation of landscapes. In 2006 the Landscape Character Network (LCN) was launched by the Countryside Agency in England with the aim of promoting LCA as a tool for understanding and managing all landscapes. 
While public sector agencies have sought to identify robust qualitative approaches to landscape evaluation, environmental economists have used a variety of economic methods to provide quantitative estimates of public preferences for landscapes (e.g. Drake, 1992; Garrod and Willis, 1992; Pruckner, 1995; Gonzalez and Leon, 2003). The majority of these studies have sought to place a monetary estimate on the benefits that particular landscapes generate for a given population.

For example, a report by Entec and Hanley (1997) investigated landscape improvements in British forests using various expressed preference methods. Their study assessed WTP per household per year for forest shape; felling method; species mix in autumn, winter, and spring. WTP for the ideal forest landscape was inferred by summing these variables, and produced a value of $£ 38.15$ per household per year. A separate contingent valuation study indicated that households would be willing to pay $£ 29.16$ per year to see enhancements in the appearance of British forests that resulted in the perception of an "ideal" forest emerging.

Visual representations of landscapes (principally photographic material or images) have long been used as an alternative method of on-site evaluation in environmental psychology and landscape perception research (e.g. Daniel and Vining, 1983; Stewart et. al., 1984; Garcia Perez, 2002) and, to a limited extent, in environmental valuation studies (e.g. Willis and Garrod, 1992). This is largely due to the fact that photographic material and/or images have been shown to be a useful and cost-effective aid to respondents' visualization of the landscape attributes being studied (e.g. Shuttleworth, 1980; Tahvanainen et. al. 2001).

Several studies have shown that landscape preferences based on photographic material used as surrogates for actual landscapes correspond closely (high positive correlations) to responses elicited by direct landscape experience-the so called 'representational validity' of photographic information. For example, Hull and Stewart (1992) compared hikers on-site and photo-based ratings of scenic beauty for a sample of mountain landscape scenes. Comparisons of group means for the views studied showed consistently high positive correlations (averaging about 0.90 ) between on-site ratings of scenic beauty and ratings by the same hikers based on colour prints mailed to their homes several months later. These results are supported by Stewart et al. (1984) who also found that landscape quality assessments based on photographic information closely matched assessments based on direct landscape experience.

Although photographic materials have been the most frequently used tool in landscape perception research, an important limitation, however, is that future or hypothetical conditions cannot be adequately represented. However, recent advances in computer visualisation technology overcame this limitation by providing controlled visual simulations. Where possible, these simulations can be integrated with biophysical data associated with alternative future environmental conditions or, to enhance real world realism, be linked to spatial data such as forest inventory data. Computer visualisation techniques have been successfully applied in assessments of landscape scenic quality 
(Orland, 1992; Swaffield and Fairweather, 1996) and development effects on landscape quality judgements and preferences (e.g. Schroeder and Orland, 1994).

Other studies (e.g. Karjalainen et. al. 2002, Al-Kodamy, 1999) have compared different visualisation methods. These studies suggest that computer-based visualisation techniques will increasingly make an important contribution in the evolution of participatory landscape planning and design. More recently, representational validity studies have extended to computer visualisations, where high realism visualisations have supported landscape quality assessments that correlate highly with photographic representation and, by implication, with direct observation of landscapes (Meitner, 2004; Bishop and Hull, 1991; Daniel and Meitner, 2001). Following these studies, the use of visual representations in our research design (discussed in the next section) benefited from the knowledge that they have been shown to be valid representations of reality.

\section{METHODOLOGY}

This study adopted a choice experiment approach to investigate public WTP for visual access to the generic forest landscapes. Choice experiments are commonly used to determine individuals' preferences for the attributes of a good or service. This is achieved within a questionnaire framework where respondents are asked to make choices between alternative 'profiles' of environmental goods. Each profile is described by various levels of a set of attributes (characteristics) of the environmental good, and the levels these take; each alternative is thus a unique combination of attributes and their levels. The alternatives are constructed using experimental design theory (Louviere et al., 2000). By including an attribute which shows the cost to the individual of each choice alternative, the economic value or WTP for a change in any of the attributes can be inferred. The choice experiment method has its theoretical grounding in Lancaster's characteristics theory of value (Lancaster, 1966) and an econometric basis is random utility theory (McFadden, 1974; Ben-Akiva and Lerman, 1985).

As outlined earlier, the main objective of the study was to estimate individuals' WTP for different forest landscapes. The profiles used in the choice experiment had therefore to encourage respondents to trade off different forest landscapes against the cost of consuming them either as views or through recreational access. The easiest way to describe a forest landscape to a respondent is through a picture, so the profiles used in the choice experiment were designed as a combination of images and text. The computergenerated images of landscapes described later in this section provided the visual element, while the text reported other attributes of the choice. The forest landscapes described in the profiles were appropriate to the local context for each survey area.

Two versions of the questionnaire were designed, differing only in the focus of the choice experiment used within them. The choice experiment in version $\mathrm{H}$ focused on respondents' preferences for views from their homes, while those in version $\mathrm{T}$ examined preferences for views on regular journeys to and from home. Respondents undertook either version $\mathrm{H}$ or version $\mathrm{T}$. This approach has the advantage of investigating two separate sources of benefit rather than just one, though splits the sample which was already constrained by the project budget to be in the region of 400 households. The split 
samples were necessary to avoid the potential confusion that could arise if choice profiles contained information about both the view that could be seen from home and the view that would be encountered on regular journeys to and from home. Such a task may be too complex for respondents and could lead to choice strategies that fail to take full account of preferences for forest landscapes seen in different circumstances.

Many different forest landscapes can be observed in the British Isles and it is beyond the scope of this study to value each of them individually. An alternative was to attempt to estimate the benefits of a range of generic landscapes that encompass the large majority of forest landscapes found in Britain.

It can be argued that the amenity benefits of any landscape feature depend, to a certain extent, upon the landscape in which they are found. Thus, the landscape benefits associated with a particular woodland configuration may vary depending on the particular landscape context. Four broad landscape contexts (mountain; plateau; hilly-rolling; and peri-urban) were selected by the FC as being relevant to this study and, within each of these, a variety of planting configurations were chosen to reflect the types of woodland commonly found in similar landscapes across Britain.

Table 1. Factors used to determine conifer forest configuration

\begin{tabular}{|c|c|c|c|c|}
\hline \multirow{2}{*}{$\begin{array}{l}\text { Configuration } \\
\text { Plateau Conifer }\end{array}$} & \multicolumn{4}{|c|}{ Factors } \\
\hline & Shape & Scale & $\begin{array}{c}\text { Structural } \\
\text { Variety }\end{array}$ & $\begin{array}{l}\text { Species } \\
\text { Variety }\end{array}$ \\
\hline 1 & Basic & Large & Low & Low \\
\hline 2 & More Organic & Large & Low & Low \\
\hline 3 & Basic & Smaller & Low & Low \\
\hline 4 & Basic & Large & High & Low \\
\hline 5 & Basic & Large & Low & High \\
\hline 6 & More Organic & Smaller & High & High \\
\hline \multicolumn{5}{|l|}{ Mountain Conifer } \\
\hline 7 & Basic & Large & Low & Low \\
\hline 8 & More Organic & Large & Low & Low \\
\hline 9 & Basic & Smaller & Low & Low \\
\hline 10 & Basic & Large & High & Low \\
\hline 11 & Basic & Large & Low & High \\
\hline 12 & More Organic & Smaller & High & High \\
\hline \multicolumn{5}{|l|}{ Hilly/Rolling } \\
\hline \multicolumn{5}{|l|}{ Conifer } \\
\hline 13 & Basic & Large & Low & Low \\
\hline 14 & More organic & Large & Low & Low \\
\hline 15 & Basic & Smaller & Low & Low \\
\hline 16 & Basic & Large & High & Low \\
\hline 17 & Basic & Large & Low & High \\
\hline 18 & More organic & Smaller & High & High \\
\hline
\end{tabular}


Forests were initially split into conifer and broad-leave categories. The FC then defined six configurations of conifer forest based on four factors: shape, scale, structural variety and species variety. For broad-leaved forests five configurations were used based on only the first three factors. Species variety was omitted for the broad-leaved category on the basis that any resulting additional configurations would not appear sufficiently different visually from those already defined and would therefore have limited usefulness in the choice experiment approach. In each case, a priori expectations based on previous experience of landscape design and its relationship with landscape benefits, suggested that the first configuration would have the lowest potential landscape value, with the final configuration having the highest potential value. The other configurations were hypothesised to have a landscape value somewhere between the two extremes. The six conifer configurations were considered within each of three landscape contexts (i.e. plateau, mountain; and hilly/rolling), yielding 18 generic conifer forest landscapes (see Table 1). Similarly the five broad-leave configurations were considered within each of the mountain; peri-urban and hilly/rolling landscapes, yielding 15 generic broad-leave forest landscapes (see Table 2).

Table 2. Factors used to determine broad-leaved forest configuration

\begin{tabular}{cccc}
\hline $\begin{array}{c}\text { Configuration } \\
\text { Mountain } \\
\text { Broadleaves }\end{array}$ & Shape & Scale & $\begin{array}{c}\text { Structural } \\
\text { Variety }\end{array}$ \\
\hline 19 & Basic & Large & Low \\
20 & More Organic & Large & Low \\
21 & Basic & Smaller & Low \\
22 & Basic & Large & High \\
23 & More Organic & Smaller & High \\
Hilly/Rolling & & & \\
Broadleaves & Basic & Large & Low \\
24 & More Organic & Large & Low \\
25 & Basic & Smaller & Low \\
26 & Basic & Large & High \\
27 & More Organic & Smaller & High \\
28 & & & \\
Peri-urban & Basic & Large & Low \\
Broadleaves & Large & Low \\
29 & Basic & Smaller & Low \\
30 & Basic & Large & High \\
31 & More Organic & Smaller & High \\
32 & & &
\end{tabular}


In consultation with the FC, consultants Cawdor Forestry were commissioned to generate images depicting each of the resulting 33 landscape configurations ${ }^{2}$. The use of visual aids such as these to investigate public preferences can bias results so care had to be taken to avoid such biases. The first concern was to avoid hypothetical biases where the respondent failed to find the images convincing. It was also important to avoid contextual biases where preferences are highly influenced by the visual representation and therefore cannot be generalised to other forest landscapes. Thus, the images used had to be both realistic representations of forest landscapes and to be relatively unexceptional and not remind respondents too strongly of any specific place.

The first question to be answered was whether it was best to use images based on traditional photo-montages or equivalent images generated by computer that were clearly realistic pictorial representations rather than photographs. Following a variety of informal pilot exercises conducted with members of the public, it was found that, although respondents regarded the computer-generated images as more obviously artificial, they found them less contrived than the photo-montages and easier to treat as generic depictions of forest landscapes particularly for the purposes of comparison.

Respondents were slow to detect differences between the photomontages and often missed certain details. By contrast, the computer-generated images made the differences between the two versions more obvious and most respondents felt them to be potentially more useful than the photomontages if they had to make choices between the paired alternatives ('once you look at the computer picture it's much easier to see what's going on in the photograph'). The computer images made it much easier to see small differences and details such as changes in the shape or species mix. A decision was therefore made to use computer-generated images in our research, while at the same time seeking to improve the quality and realism of the pictures used. The images were improved and the new versions were tested on a small sample of the general public.

The survey was undertaken in six survey areas chosen to reflect the different landscape contexts used in the forest landscape images (see Table 3). The chief criterion was that the populations living in these areas could feasibly encounter views similar to those used in the choice profiles. The 'mountain' and 'hilly/rolling' landscape contexts were each covered by the same two survey areas in different parts of the country. In these cases the samples relating to the landscape contexts were split equally across the two survey areas. Separate samples were used to cover the survey areas for the plateau and peri-urban landscape contexts.

\footnotetext{
2. A selection of images used in the study is shown in the appendix. That is configuration $2,4,11,12,15$, and 17 depicting conifer forest landscapes (see Table 1) and configuration 19, 20, 25, 28, 31, 32 depicting broad-leaved forest landscapes (see Tables 2). Due to space constraints, all the 33 images could not be included in this paper, but are available from the authors upon request.
} 
Table 3. Survey areas

\begin{tabular}{|c|c|}
\hline $\begin{array}{c}\text { Survey area and } \\
\text { associated landscape } \\
\text { context }\end{array}$ & Survey sites \\
\hline $\begin{array}{l}\text { Aberystwyth area } \\
\text { (Plateau) }\end{array}$ & $\begin{array}{l}\text { Aberystwyth, Machynlleth, Dolgellau, Trawsfynydd, villages } \\
\text { along A } 487 \text { Aberystwyth to Dolgellau }\end{array}$ \\
\hline $\begin{array}{l}\text { Chester area } \\
\text { (hilly/rolling) }\end{array}$ & $\begin{array}{l}\text { Chester, Northwich, Tarporley, Kelsall, Helsby, Kingsley, } \\
\text { Crowton, Duddon, Cuddington }\end{array}$ \\
\hline $\begin{array}{l}\text { Loch Lomond area } \\
\text { (Mountain) }\end{array}$ & $\begin{array}{l}\text { Dumbarton, Alexandria, Helensburgh, Rhu, Garelochhead, } \\
\text { Inverbeg, Luss }\end{array}$ \\
\hline $\begin{array}{c}\text { Exeter area } \\
\text { (hilly/rolling) }\end{array}$ & $\begin{array}{l}\text { Exeter, Okehampton, Postbridge, Moretonhampstead, } \\
\text { Chagford, Drewsteignton, South Tawton }\end{array}$ \\
\hline $\begin{array}{l}\text { Harlow area } \\
\text { (peri-urban) }\end{array}$ & $\begin{array}{l}\text { Harlow, Epping, Chipping Ongar, Brickenden, Epping Green, } \\
\text { Essendon, Nazeing, Wormley }\end{array}$ \\
\hline $\begin{array}{c}\text { Penrith and Keswick } \\
\text { area } \\
\text { (Mountain) }\end{array}$ & $\begin{array}{l}\text { Penrith, Keswick, Cockermouth, villages along A66 Penrith to } \\
\text { Cockermouth }\end{array}$ \\
\hline
\end{tabular}

A survey of over 416 individuals was undertaken in August/September 2002 by a professional market research company; 211 version $\mathrm{H}$ and 205 version $\mathrm{T}$ usable questionnaires were completed. The sample was stratified to ensure that a demographically representative section of the population was surveyed in both urban and rural locations. Before undertaking the choice experiment, respondents were informed that the purpose of the survey was to find out how much people in Britain valued landscapes, and that to help this investigation a series of images depicting forest landscapes had been developed. Respondents were told that, if they lived in the countryside, these were the sorts of forest landscapes they might see from their homes or during regular journeys to and from home. They were also told that it might be possible to use these landscapes for walks or other sorts of recreation.

In order to facilitate the aggregation process, the preferences of the sample should broadly reflect the preferences of those individuals who already come into regular contact with a woodland view, either from home or on their regular journeys to and from home. It was observed that 80 per cent of the sample aspired to live in a more rural location where experiencing a woodland view would be more likely. On this basis it is reasonable to assume that the preferences of our sample may not differ too greatly from those of the populations over which values will be aggregated (as many of these will indeed live in a rural or near-to-rural location).

The valuation scenario used in both versions of the questionnaire began by requesting respondents to imagine that they were about to move to the country. In version $\mathrm{H}$ of the questionnaire, respondents were then asked to consider a situation where, having examined all of the housing possibilities in their chosen area within their price range, they have arrived at a short list of their three favourites. The only significant differences between these three alternatives are: 
- the view

- recreational access to the view;

- the annual cost of living there, e.g. council tax, the cost of travelling to work, and rent or mortgage.

The valuation scenario used in version $\mathrm{T}$ differed only in stating that the views and any associated recreational access would be encountered during regular journeys to and from home. The choice to be made by respondents was illustrated using three profiles. Each profile consisted of a computer-generated image of the view, coupled with some text giving information about possible recreational access to the view and the associated cost relative to the cheapest option (see Figure 1).

Figure 1. Example of profile set used in choice experiment

\begin{tabular}{|c|c|c|}
\hline BASELINE PROFILE & PROFILE 1 & PROFILE 2 \\
\hline $\begin{array}{c}\text { IMAGE OF } \\
\text { CONTEXTUAL } \\
\text { LANDSCAPE WITHOUT } \\
\text { WOODLAND }\end{array}$ & $\begin{array}{c}\text { IMAGE OF } \\
\text { CONTEXTUAL } \\
\text { LANDSCAPE WITH } \\
\text { WOODLAND }\end{array}$ & $\begin{array}{c}\text { IMAGE OF } \\
\text { CONTEXTUAL } \\
\text { LANDSCAPE WITH } \\
\text { WOODLAND }\end{array}$ \\
\hline Recreational Access? & Recreational Access? & Recreational Access? \\
\hline No & Yes & No \\
\hline $\begin{array}{l}\text { Additional cost of having } \\
\text { this view? }\end{array}$ & $\begin{array}{l}\text { Additional cost of having } \\
\text { this view? }\end{array}$ & $\begin{array}{l}\text { Additional cost of having } \\
\text { this view? }\end{array}$ \\
\hline$£ 0$ - cheapest option & $£ 150$ & $£ 100$ \\
\hline
\end{tabular}

The three profiles in each choice were based on an orthogonal fractional factorial experimental design (Louviere et al., 2000) based on three attributes (i.e. forest configurations - either five broad-leaved or six conifer; recreational access - yes or no; and additional costs - six levels). The costs used in version $\mathrm{T}$ were lower than version $\mathrm{H}$ reflecting the probable higher utility of views and recreational access from home compared with regular journeys. As stated by Batsell and Louviere (1991), one should ideally design the attributes of all choice profiles to be orthogonal both within and between all alternatives. This means that each profile is independent of all other alternatives and that the levels of each attribute are evaluated independently of all the levels of other attributes thus avoiding the problem of multicolinearity 
Each of the three profiles in a given choice set depicted views looking over the same landscape context: either mountain, plateau, hilly-rolling, or peri-urban. The first alternative (baseline profile) was cheaper than the others and did not offer a forest view. The others cost more but offered views of forests. For any respondent the type of forest shown in these views (i.e. conifer or broad-leaved) remained constant across profiles and choices and only the forest configuration varied. An attribute detailing opportunities for recreational access was included in the profile to ensure that respondents explicitly took this factor into account when making their choices. If the attribute had been omitted, then experience suggests that some respondents would have made their choices (and their WTP) on the assumption that recreational access would be available in the landscape in question. The payment vehicle used here was the additional cost to the respondent of living in an area which would provide access to this view (either from home or on regular journeys). This additional cost comprised increases to council tax, rent or mortgage and travel to work costs.

The design adopted in this study allows WTP for both visual and recreational access to the forest landscape to be estimated separately. In the choice sets used here, no recreational access was available in the baseline profile, while such opportunities might or might not be available in the two more expensive options. Having been provided with this information about views, recreational access and cost, respondents were asked to select the alternative they most preferred or one they like best. This exercise was completed four times by each respondent.

A small pilot survey was conducted to test the questionnaire and the choice experiment. Respondents were able to successfully complete the choice experiment exercises and when questioned did not reveal that they had experienced any problems due to either the nature of the choice cards and the associated images or the other attributes (including the additional costs attribute).

The choice experiment approach has been applied to estimate the impacts on economic welfare from changing the provision of public goods in the US and Europe (e.g. Opaluch et al., 1993; Adamowicz et al., 1994; Garrod et al, 2002). The technique has also been used to assess the general public's preferences or WTP for different forest management standards (e.g. Garrod and Willis, 1997) or to examine public preferences for the attributes of agricultural landscapes (Rambonilaza et al. 2007). In this paper, the multinomial logit model (McFadden, 1974; Louviere et al., 2000) was employed to derive estimates of individual's WTP for views of the different forest landscapes investigated. The multinomial logit model is the most common way of analysing results from choice experiments econometrically. The interested reader is referred to the above literature for a more in-depth description of the theory and econometric analysis of choice experiment data. The results based on a selection of multinomial logit models estimated are discussed in the following sections. 


\section{RESULTS}

\subsection{Landscape preferences}

Respondents were asked about the landscapes that they would prefer to live in, compared to the landscapes where they currently live (see Figure 2). The results are interesting, showing very high preferences for upland and coastal landscapes, in some of which woodland may not be a characteristic feature.

Figure 2. Respondents preferences for landscape types

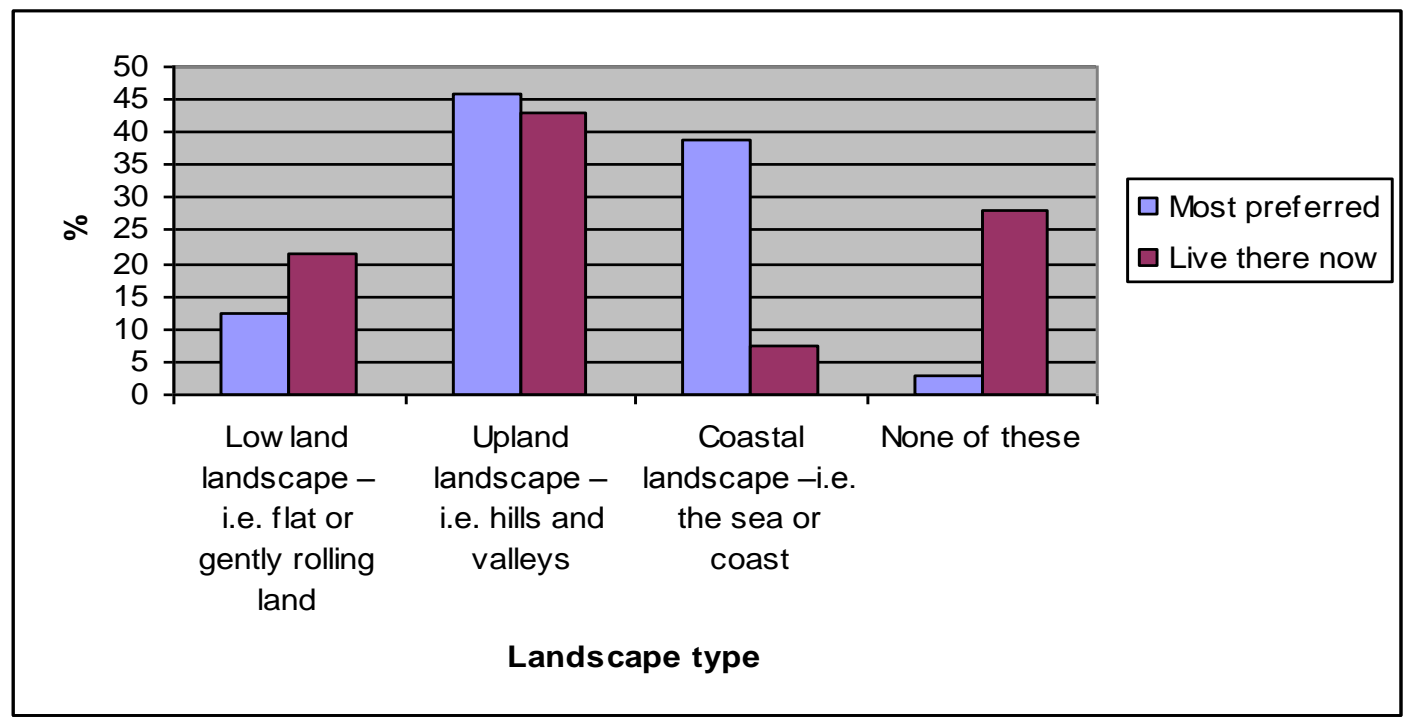

In preparation for the choice experiment, respondents were asked to rate a range of eight factors in order of their importance when choosing a place to live, nearly 30 per cent rated 'nice views' as one of the three most important, nearly 45 per cent felt that 'green or open spaces' ranked in the top three, while over 25 per cent felt the same about 'being near to walks and other recreational opportunities' ('being close to shops and other services', 'low levels of crime', and 'peace and quiet' were all rated as more important). This suggests that there are likely to be positive preferences for forest landscapes, provided that respondents find the resulting views aesthetically pleasing, or have positive preferences for any recreational opportunities offered by the forests.

Respondents were also asked about their preferences for the types of forest that they would like to see in a view. The results of this investigation were quite revealing, suggesting that the sample had well defined preferences about the characteristics of forests that they would like to see in a view. Preferences across the seven choices shown in Table 4, suggest that a 'typical' respondent prefers small woodlands comprising stands of randomly spaced broad-leaves of varying heights, interspersed with areas of open space. The majority of respondents also preferred to see woodlands on hills and away 
from towns. This result may, of course, reflect general landscape preferences rather than opinions about forests, and more than half of respondents had at least an equal preference for seeing forests on flatter land or near towns.

Table 4. Respondents' preferences for different forest characteristics

\begin{tabular}{|c|c|c|c|c|}
\hline $\mathbf{S}$ & Coniferous trees & Broad-leaved trees & Equal preference & Neither \\
\hline $\begin{array}{l}\mathbf{e} \\
\mathbf{t} \\
\mathbf{1}\end{array}$ & $13.7 \%$ & $54.6 \%$ & $30.8 \%$ & $1.0 \%$ \\
\hline $\begin{array}{l}\mathbf{S} \\
\mathrm{e}\end{array}$ & Large forests & Small woodlands & Equal preference & Neither \\
\hline $\begin{array}{l}\mathbf{t} \\
2\end{array}$ & $22.4 \%$ & $57.2 \%$ & $19.2 \%$ & $1.2 \%$ \\
\hline $\begin{array}{l}\mathbf{S} \\
\mathbf{e} \\
\mathbf{t}\end{array}$ & $\begin{array}{c}\text { Trees of various } \\
\text { heights }\end{array}$ & $\begin{array}{l}\text { Trees that are all } \\
\text { similar heights }\end{array}$ & Equal preference & Neither \\
\hline 3 & $74.8 \%$ & $9.9 \%$ & $14.7 \%$ & $0.7 \%$ \\
\hline $\begin{array}{l}\mathbf{S} \\
\mathbf{e} \\
\mathbf{t}\end{array}$ & $\begin{array}{l}\text { A mix of trees and } \\
\text { open spaces }\end{array}$ & Just trees & Equal preference & Neither \\
\hline 4 & $83.4 \%$ & $5.3 \%$ & $10.8 \%$ & $0.5 \%$ \\
\hline $\begin{array}{l}\mathbf{S} \\
\mathrm{e} \\
\mathbf{t}\end{array}$ & $\begin{array}{l}\text { Regularly spaced } \\
\text { trees }\end{array}$ & $\begin{array}{c}\text { Randomly spaced } \\
\text { trees }\end{array}$ & Equal preference & Neither \\
\hline 5 & $10.1 \%$ & $77.4 \%$ & $11.8 \%$ & $0.7 \%$ \\
\hline $\begin{array}{l}\mathrm{S} \\
\mathrm{e} \\
\mathrm{t}\end{array}$ & Trees on hills & $\begin{array}{l}\text { Trees on flatter } \\
\text { land }\end{array}$ & Equal preference & Neither \\
\hline 6 & $49.0 \%$ & $14.7 \%$ & $35.6 \%$ & $0.7 \%$ \\
\hline $\begin{array}{l}S \\
\mathrm{e} \\
\mathrm{t}\end{array}$ & Near to towns & $\begin{array}{l}\text { Away from } \\
\text { towns }\end{array}$ & Equal preference & Neither \\
\hline 7 & $32.2 \%$ & $38.5 \%$ & $27.6 \%$ & $1.7 \%$ \\
\hline
\end{tabular}

Of all the preferences investigated, the strongest were for woodland that mixed trees and open space and where spacing of trees was random rather than regular. If these preferences were translated to the factors that determined the forest configurations used in the choice experiment, it might be expected that respondents would prefer shape to be 'more organic' rather than 'basic'; scale to be 'small' rather than 'large'; structural variety to be 'high' rather than 'low'; and species variety to be high' rather than 'low'. If preferences for these attributes are separable and additive, then those configurations that offer all of the favoured factors (e.g. configurations 6, 12, 18, 23 and 28 in Tables 1 and 2 ) should attract the highest values. This result may not be observed if respondents either fail to see the preferred factors reflected in the images provided or if their preferences for 
combinations of factors do not reflect preferences for those factors when considered individually.

\subsection{Results from the choice experiments}

As previously described, the choice experiment used in this study required individuals to select their most preferred alternative from the set of three forest landscape profiles. The attribute levels of each profile are used along with data on choices to estimate a discretechoice, utility-maximising model for the sample data. The estimated parameters of the model are then used to estimate the trade-off which respondents make between disposable income and a change in the provision of the access to forest landscapes described in the choice sets. For any particular specification 12 separate models could be estimated, split evenly between the two different versions of the questionnaire. For each version the six models corresponded to the six generic forest landscape types investigated by the study.

The estimates reported in Table 5 are based on an attributes-only specification of the model, rather than ones in which individual specific characteristics are also incorporated. Such models have been estimated but the relatively small sample sizes mean that the impacts of respondent-specific characteristics are not consistent. The Tables reveal that robust WTP estimates cannot be estimated for a number of configurations (e.g. those involving plateau conifer landscapes) due to a lack of statistically significant coefficient values. In other cases there is evidence that respondents experience a loss in welfare associated with certain forests in particular landscapes (e.g. broad-leaves in a mountain setting). Clear preferences for forested landscapes compared with the non-forested alternatives are only found for broad-leaved woodland in a peri-urban setting. 
Table 5. Annual household WTP for views of forest configurations ( $£$, per household per year)

\begin{tabular}{lcc}
\hline $\begin{array}{c}\text { Planting } \\
\text { configuration }\end{array}$ & $\begin{array}{c}\text { From } \\
\text { Home }\end{array}$ & $\begin{array}{c}\text { On Regular } \\
\text { Journeys }\end{array}$ \\
$\begin{array}{l}\text { Plateau conifer } \\
\text { Mountain conifer }\end{array}$ & $\mathrm{n} / \mathrm{s}$ & \\
10 & $£ 99.94$ & - \\
$\begin{array}{c}\text { Hilly/rolling conifer } \\
16\end{array}$ & - & $-£ 88.64$ \\
17 & $-£ 310.39$ & - \\
Mountain broad-leaves & & \\
19 & $-£ 398.25$ & - \\
20 & $-£ 363.66$ & - \\
21 & $-£ 368.36$ & - \\
22 & $-£ 559.05$ & - \\
23 & $-£ 398.52$ & \\
Hilly/rolling broad-leaves & & \\
& $\mathrm{n} / \mathrm{s}$ & $£ 264.97$ \\
Urban fringe broad-leaves & & $£ 191.97$ \\
29 & $£ 265.44$ & $£ 157.88$ \\
30 & $£ 239.62$ & $£ 219.70$ \\
31 & $£ 199.45$ & \\
32 & $£ 273.33$ & \\
\hline
\end{tabular}

$\mathrm{n} / \mathrm{s} \quad$ Coefficients on cost and view not significant at $10 \%$ level; all the other

coefficients are significant at 5 or 10 per cent level.

The lack of significant WTP values associated with certain landscape contexts is a cause for concern. The study design was such that relatively few respondents (i.e. 30-40) made choices using the same sets of choice profiles. Given that respondents undertook four choice experiments each this meant that WTP values were based on a maximum of 160 choices from 40 individuals. While this should be a large enough sample to generate robust estimates of WTP, low sample sizes increase the probability of sample-selection effects. That said, the incidence of significant results across the two different versions of the questionnaire is quite consistent with, for example, strongly significant positive coefficients estimated for views over peri-urban broad-leave landscapes from both samples. The negative coefficients associated with views of broad-leaved woodlands in mountain areas are also observed in both samples. The results may therefore reflect indifference among the population regarding certain forested landscapes or dissonance in preferences across the population.

In both samples there were no systematic links between the magnitude of WTP and incidence of the forest design factors shown in Table 4 to be those most favoured by respondents. It is possible that the combination of different factors and their depiction in 
the images presented to respondents may have resulted in quite different visual impacts to those expected by respondents when considering verbal descriptions of those factors.

While the values estimated above are useful from a planning perspective at the individual forest level, this study requires some aggregate estimate of the landscape value of forests. The magnitude of the populations who have visual access to specific forest landscape configurations cannot be estimated at present. It is, however, possible to estimate the size of the relevant populations for certain of the broader generic landscape categories within which the individual configurations sit. This suggests that for the purposes of aggregation, WTP values are required for the six generic forest landscape categories listed in Tables 1 and 2. If the choice models are run with an alternative specification that ignores forest configuration and considers only whether or not woodland is present or absent in a given profile, then it is possible, in some cases, to generate a WTP estimate for views of forests in the various generic landscape contexts (see Table 6).

Table 6. WTP for forest views in generic landscape contexts: (£, per household per year)

\begin{tabular}{lcc}
\hline \multicolumn{1}{c}{$\begin{array}{c}\text { Generic Forest } \\
\text { Landscapes }\end{array}$} & From Home & While Travelling \\
\hline Plateau conifer & $\mathrm{n} / \mathrm{s}$ & $\mathrm{n} / \mathrm{s}$ \\
Mountain conifer & $\mathrm{n} / \mathrm{s}$ & $\mathrm{n} / \mathrm{s}$ \\
Hilly/rolling conifer & $\mathrm{n} / \mathrm{s}$ & $\mathrm{n} / \mathrm{s}$ \\
Mountain broad-leaves & $-£ 442.39$ & $-£ 101.68$ \\
Hilly/rolling broad-leaves & $\mathrm{n} / \mathrm{s}$ & $\mathrm{n} / \mathrm{s}$ \\
Urban fringe broad-leaves & $£ 268.79$ & $£ 226.56$ \\
\hline
\end{tabular}

The most important values in terms of magnitude of WTP and size of affected populations are for views of broad-leaved woodland in peri-urban areas. Table 7 reports coefficient values for the peri-urban model.

Table 7. Model coefficients for views of peri-urban broad-leaved landscapes

\begin{tabular}{lcc}
\hline \multicolumn{1}{c}{ VARIABLES } & $\begin{array}{c}\text { From home } \\
\text { (t-value) }\end{array}$ & $\begin{array}{c}\text { On regular journeys } \\
\text { (t-value) }\end{array}$ \\
\hline Woodland view & 2.2266 & 1.7945 \\
& $(5.48)$ & $(3.0)$ \\
Recreational Access & 1.1154 & 1.6498 \\
& $(3.68)$ & $(5.27)$ \\
Additional Cost & -0.0082838 & -0.0079207 \\
& $(-4.75)$ & $(-1.50)$ \\
Log-likelihood & & -95.224 \\
Pseudo R & -99.285 & 0.343 \\
\hline
\end{tabular}




\subsection{Estimates of recreational benefits}

The design of the choice experiment permits estimation of WTP for recreational access to forest landscapes. WTP estimates were generated for the six broad forest landscape categories rather than for the individual configurations. This was partly based on analytical considerations, but more fundamentally reflected the expectation that respondents would not be able to make detailed distinctions between the recreational opportunities offered by particular planting configurations within a broad forest landscape category.

Table 8. Annual household WTP for recreational opportunities associated with generic forest landscapes

\begin{tabular}{lcc}
\hline \multicolumn{1}{c}{ Generic landscape } & From home & On journeys \\
\hline Plateau conifer & $\mathrm{n} / \mathrm{s}$ & $\mathrm{n} / \mathrm{s}$ \\
Mountain conifer & $£ 141.36$ & $\mathrm{n} / \mathrm{s}$ \\
Hilly/rolling conifer & $\mathrm{n} / \mathrm{s}$ & $£ 91.39$ \\
Mountain broad-leaves & $£ 369.29$ & $\mathrm{n} / \mathrm{s}$ \\
Hilly/rolling broad-leaves & $£ 155.75$ & $£ 61.09$ \\
Urban fringe broad-leaves & $£ 171.10$ & $£ 179.91$ \\
\hline n/s Coefficients on cost and view not significant at 10\% level; all the other \\
coefficients are significant at 5 or 10 percent level
\end{tabular}

Table 8 reports estimates of the recreational benefits associated with each of the broad forest landscape categories for both versions of the questionnaire. Estimated recreational benefits are in some cases lower than landscape benefits, though in several instances recreational benefits could be estimated when landscape benefits could not. In the majority of cases, respondents who would see the forest landscape from home would have higher recreational benefits than those passing the forests on their regular journeys. This is explained by the fact that the former probably have more opportunities to take advantage of the recreational opportunities. The only exception is for recreational opportunities on the urban fringe, where values are almost identical for both samples. This suggests that respondents felt that access to these recreational opportunities would be straightforward given that they would be located near to towns.

While these recreational benefit estimates are of interest, they cover only a subset of the population. More comprehensive estimates of forest recreation benefits are provided in Scarpa (2003). Even so, if used in the aggregation exercise along with the visual amenity benefits reported earlier, these estimates would substantially increase the overall estimate of aggregate forest landscape benefits.

\subsection{Aggregation}

The aggregate landscape value of woodland should be based upon the number of households with views of the different types of forest landscapes. However, estimating the number of residential properties in each of the broad landscape categories through a 
GIS system, such as ARCVIEW, using 'viewsheds' to determine which properties have views of woodland and which do not, is a task well beyond the resources available to this project. An alternative approach to establishing the number of households over which aggregation should proceed would have been to estimate the number of households with a certain distance, say $3 \mathrm{~km}$, of woodland in specific types of landscape. Unfortunately the FC was unable to provide data on the number of households living within a certain distance of woodland landscape types in spatial areas of Great Britain.

The method eventually adopted to aggregate WTP for views of broad-leave woodland in peri-urban landscapes was based on the 1991 Census classification of wards. This classified wards into: (i) wholly rural; (ii) predominantly rural (1-25\%); (iii) mixed rural (25-50\%); (iv) mixed urban (50-75\%); (v) predominantly urban (75\%+); and (vi) wholly urban. GIS was used to identify mixed-urban wards by regions in Great Britain. The number of households in these wards was summed to provide an estimate of the number of urban fringe households. These household totals amounted to 795,912 in England (0.04216 of all households in England); and 52,220 in Wales (0.04663 of all households in Wales). The Scottish census did not classify wards into rural-urban types. Hence, the average proportion of mixed urban wards in England and Wales (0.04241) was used to estimate the number of households in mixed urban wards in Scotland $(86,290)$ from the total number of Scottish households $(2,035,134)$.

To estimate the number of households with woodland views in peri-urban areas, by regions of Great Britain the number of urban fringe households was multiplied by the proportion of households in the survey $(0.23)$ who reported that they both lived 'on the edge of town and country' and had a view over woodland from their home. To estimate aggregate landscape value the regional household totals of urban fringe households with woodland views were multiplied by the estimated annual WTP (£269) for the "withwithout' woodland scenario (see Table 6), capitalised at a $3.5 \%$ discount rate into perpetuity. The capitalised value amounted to $£ 7,680$ per household. Table 9 documents the estimated number of households with a woodland view, and summarises the aggregate value of woodland landscape by country in $£$ millions.

Table 9. Aggregate value of woodland landscape

\begin{tabular}{lccccc}
\hline Area & $\begin{array}{c}\text { Number of } \\
\text { households } \\
\text { with woodland } \\
\text { view }\end{array}$ & $\begin{array}{c}\text { Value of } \\
\text { woodland } \\
\text { view for } \\
\text { houses } \\
(£, \text { millions })\end{array}$ & $\begin{array}{c}\text { Number of } \\
\text { households } \\
\text { seeing } \\
\text { woodland } \\
\text { on journey }\end{array}$ & $\begin{array}{c}\text { Value of } \\
\text { woodland } \\
\text { view on } \\
\text { journeys } \\
\text { per } \\
\text { household } \\
\text { (£, millions }\end{array}$ & $\begin{array}{c}\text { Total value } \\
\text { of views of } \\
\text { urban } \\
\text { fringe } \\
\text { woodland } \\
(£, \text { millions }\end{array}$ \\
\hline England & 183,324 & 1407.88 & 329,444 & 2132.54 & 3540.42 \\
Scotland & 19,875 & 152.63 & 60,506 & 391.66 & 544.29 \\
Wales & 12,028 & 92.37 & 17,733 & 114.79 & 207.16 \\
$\begin{array}{l}\text { Great } \\
\text { Britain }\end{array}$ & 215,227 & 1652.88 & 407,683 & 2638.99 & 4291.87 \\
\hline
\end{tabular}


This study estimates that an average household was willing to pay $£ 226$ per year for views of urban fringe broad-leaved woodland on journeys. Views of woodland in other landscape settings were either very small or statistically insignificant. The aggregate value of urban fringe broad-leaved woodland was estimated by calculating the proportion of population in predominantly rural wards plus mixed rural wards who commuted outside the district, from the 1991 Census. Applying this proportion to households provides an estimate of the number of households who commute outside the district. Assuming that these households commute into an urban area, the number of households that commute can be multiplied by the probability that they encounter an urban fringe broad-leaved woodland on their journey. The FC estimated that $15.5 \%$ of the urban and urban fringe area has tree cover. This figure was used as the probability of encountering a woodland view on a journey. The capitalised value, at $3.5 \%$, of the average household's WTP for views of urban fringe broad-leaved woodland on journeys, is $£ 6473$. This capitalised value was multiplied by the number of commuting households who encounter this woodland. The results are reported in Table 8.

The capitalised value of forest landscape of $£ 7,680$ per house is consistent with the results of previous hedonic price models that have estimated the contribution of trees to house prices. Local trees were estimated by Anderson and Cordell (1988) to add 4\% to house prices, whilst Morales (1980) estimated they added 6\%. Garrod and Willis (1992) estimated that at least $20 \%$ general tree cover adjacent to a house added $7.1 \%$ to property prices.

\section{CONCLUSIONS}

The objective of this study was to provide data from which robust estimates of aggregate forest landscape benefits could be derived. To achieve this, a questionnaire survey was used as the vehicle for a series of choice experiments designed to investigate how much people are willing to pay for visual or recreational access to the different configurations of forest landscape depicted in a series of computer-generated images. The study considered 11 different forest configurations based on a variety of factors and investigated preferences for these designs across a number of contextual landscapes. A total of 33 forest landscapes were therefore available for use in the choice experiment. The definition of such a wide range of forest landscapes allowed us to investigate the hypothesis that preferences for forest design are not constant across different landscape contexts.

Two versions of the choice experiment were designed that respectively aimed to estimate public WTP for views of forest landscapes from home and on regular journeys. Analysis of over 1600 responses to the choice experiment from 416 respondents, generated statistically significant coefficient values from which to estimate WTP values for a number of the forest landscapes. The results indicate that preferences for different forest configurations are indeed highly dependent on the landscape contexts within which they are found. The highest and most significant WTP values were associated with broadleave woodland in peri-urban landscapes. No significant WTP values could be estimated for the majority of landscapes and in several cases negative WTP values compared to the landscape without trees were observed. In general, WTP for views from home was larger 
than for views on regular journeys and WTP for recreational access was also significant in a number of cases. Due to the relatively small sample sizes used in the study, these findings require further investigation before they are used in detailed policy analysis.

Due to difficulties in identifying populations with access to the forest landscapes investigated in this study, the aggregation exercise concentrated on those households with visual access to broad-leaved woodland in peri-urban landscapes. These landscapes attract the highest WTP values and impact on large proportions of the population of Great Britain. WTP for views from home over peri-urban broad-leave forest landscapes was $£ 269$ per household per year, falling to $£ 227$ for views on regular journeys.

These values were capitalised and aggregated across the proportion of the population of Great Britain estimated to have regular visual access to these landscapes either from home or while travelling. The resulting aggregate capitalised value is over $£ 4$ billion, with an annual present value of $£ 150$ million. Such values are substantial and demonstrate the considerable contribution that forest landscapes make to the welfare of individuals with regular visual access. Adding estimated recreational value to these figures would increase them by around 60 per cent, while the contribution made by some other forest landscapes not included in the aggregation exercise would also be significant.

These values confirm the importance of landscape in contributing to the social and environmental benefits provided by forests and suggests that current policies of woodland expansion may generate additional benefits especially if more woodland is located close to urban populations. Forest planning should assign appropriate weighting to landscape values in these areas. Indeed a number of current activities such as the community woodland programmes in Great Britain already focus on providing multiple benefits to populations in and around urban areas.

The use of computer-generated images of forest landscapes proved highly successful within the choice experiment. A further study could use forest design attributes listed in Tables 1 and 2 to generate an orthogonal set of forest configurations which could then be translated into images for use within a choice experiment. This would allow a structured investigation of design attributes within landscape contexts rather than forest configurations. The results of such an exercise could be compared with the qualitative comparisons reported in Table 3 which suggested that the public have preferences for smaller woodlands comprising of stands of randomly spaced broad-leaves of varying heights, interspersed with areas of open space. Similarly, future studies could incorporate woodlands containing a mix of broadleaves and conifers similar to those found in parts of Scandinavia and Canada. 


\section{References}

ADAMOWICZ, W.L., LOUVIERE, J.J. \& WILLIAMS, M. (1994) Combining revealed and stated preference methods for valuing environmental amenities. Journal of Environmental Economics and Management. 26, 271-292.

AL-KODAMY, K. (1999) Using visualization techniques for enhancing public participation in planning and design: process, implementation, and evaluation. Landscape and Urban Planning, 45, 37-45.

ANDERSON, L.M. (1981) Land use designations affect perception of scenic beauty in forest landscapes. Forest Science, 27, 392-400.

ANDERSON, L.M. \& CORDELL, H.K. (1988) Influence of trees on residential property values in Athens, Georgia USA: a survey based on actual sales prices. Landscape and Urban Planning. 15, pp. 153-164.

ANGILERI, V., \& TOCCOLINI, A. (1993) The assessment of visual quality as a tool for the conservation of rural landscape diversity. Landscape and Urban Planning, 24, 105112 .

BATSELL, R.R. \& LOUVIERE, J.J. (1991) Experimental analysis of choice. Marketing Letters, 2, 99-241.

BEN-AKIVA, M. \& LERMAN, S. (1985) Discrete Choice Analysis: Theory and Application to Travel Demand, Massachusetts, MIT Press.

BISHOP, I.D. \& HULL, R.B. (1991) Integrating technologies for visual resource management. Journal of Environmental management, 32, 295-312.

BURGESS, J. (1995) Growing in confidence - Understanding People's Perceptions of Urban Fringe Woodlands, Countryside Commission, Cheltenham.

COBHAM RESOURCE CONSULTANTS (1993) Landscape Assessment Guidance. CCP 423, Countryside Commission, Cheltenham.

DANIEL, T. C. \& VINING, J. (1983) Methodological issues in the assessment of landscape quality, in: I. Altman \& Wohlwill, J. (Eds.), Human Behaviour and Environment, New York, Plenum

DANIEL, T.C. \& MEITNER, M. (2001) Representational validity of landscape visualisations: the effects of graphical realism on perceived scenic beauty of forest vistas. Journal of Environmental Psychology, 21, 61-72.

DRAKE, L (1992), The non-market value of agricultural landscape, European Review of Agricultural Economics, 19, 351-364. 
ELEFTHERIADIS, N. \& TSALIKIDIS, I. (1990) Coastal pine forest landscapes: modelling scenic beauty for forest management. Journal of Environmental Management, $30,47-62$.

ENTEC, N.D. \& HANLEY, N. (1997) Valuing Landscape Improvements in British Forests. Report to the Forestry Commission, Entec UK, Leamington Spa, Environmental Economics Research Group, University of Stirling.

FC (FORESTRY COMMISSION) (1991) Statement of Forestry Policy for Great Britain, Forestry Commission, Edinburgh.

FC (FORESTRY COMMISSION) (2004) The UK Forestry Standard: the government's approach to sustainable forestry, Forestry Commission, Edinburgh.

GARCIA PEREZ, J.D. (2002) Ascertaining Landscape Perceptions and Preferences with Pair-wise Photographs: planning rural tourism in Extremadura, Spain. Landscape Research, 27, 297-308.

GARROD, G.D., SCARPA, R. \& WILLIS, K.G. (2002) Estimating the benefits of traffic calming on through routes: a choice experiment approach. Journal of Transport Economics and Policy, 36, 211-231.

GARROD, G.D. \& WILLIS, K.G. (1992) Valuing goods' characteristics: an application of the hedonic price method to environmental attributes. Journal of Environmental Management, 34, pp. 59-76.

GARROD, G.D. \& WILLIS, K.G. (1997) The non-use benefits of enhancing forest biodiversity: a contingent ranking study. Ecological Economics, 21, 45-61.

GONZALEZ, M. \& LEON, C.J. (2003) Consumption process and multiple valuation of landscape attributes. Ecological Economics, 45, 159-169.

Holgén, P. \& Lind, T. (1995) How do adjustments in the forest landscape resulting from environmental demands affect the costs and revenues to forestry? Journal of Environmental Management, 45, 177-187.

HULL, R. B. \& STEWART, W.P. (1992) Validity of photo-based scenic beauty judgements. Journal of Environmental Psychology, 12, 101-114.

JORGENSEN, A. \& ANTHOPOULOU, A. (2007) Enjoyment and fear in urban woodlands - Does age make a difference? Urban Forestry and Urban Greening, 6, 267278

KARJALAINEN, E. \& TYRVAINEN, L. (2002) Visualisation in forest landscape preference research: a Finnish perspective. Landscape and Urban Planning, 59, 13-28. 
LANCASTER, K.J. (1966) A New Approach to Consumer Theory. Journal of Political Economy, 74, 32-157.

LOUVIERE, J.J., HENSHER, D.A. \& SWAIT., J.A. (2000) Stated Choice Methods: Analysis Application, Cambridge, Cambridge University Press.

MCFADDEN, D. (1974) Conditional logit analysis of qualitative choice behaviour, in: Zarembka, P.E. (Ed.), Frontiers of Econometrics, New York, Academic Press.

MEITNER, M.J. (2004) Scenic beauty of river views in the Grand Canyon: relating perpetual judgements to locations. Landscape and Urban Planning, 68, 3-13.

MORALES, D.J. (1980) The contribution of trees to residential property values. Journal of Arboriculture, 6, 305-308.

OFFICE OF THE DEPUTY PRIME MINISTER (2004) Planning Policy Statement 7: Sustainable Development in Rural Areas. The Stationary Office, London.

OPALUCH, J.J., SWALLOW, S., WEAVER, T., WESSELS, C. \& WICHLENS, D. (1993) Evaluating impacts from noxious waste facilities, including public preferences in current sitting mechanisms. Journal of Environmental Economics and Management, 24, 41-59.

ORLAND, B. (1992) Data visualisation techniques in environmental management: research, development and application plan. Landscape and Urban Planning, Special Issue, 21.

PRUCKNER, G. J. (1995) Agricultural Landscape Cultivation in Austria: An Application of the CVM. European Review of Agricultural Economics, 22, 173-190.

RAMBONILAZA, M \& DACHARY-BERNARD, J. (2007) Land-use planning and public preferences: What can we learn from choice experiment method? Landscape and Urban Planning, 83, 318-326.

SCARPA, R. (2003) Recreation. Social and Environmental Benefits of Forestry: Phase 2. Report to the Forestry Commission, Edinburgh. Centre for Research in Environmental Appraisal and Management, Newcastle University.

SCHROEDER, H.W. \& ORLAND, B. (1994) Spatial characteristics of urban park tree plantings. Environmental Management, 18, 119-128.

SHUTTLEWORTH, S. (1980) The use of photographs as an environmental presentation medium in landscape studies. Journal of Environmental Management, 11, pp. 61-76. 
STEWART, T. R., MIDDLETON, P., DOWNTON, M. \& ELY, D. (1984) Judgements of photographs versus field observations in studies of perception and judgement of the visual environment, Journal of Environmental Psychology, 4, 283-302.

SWAFFIELD, S.R. \& FAIRWEATHER, J.R. (1996) Investigation of attitudes toward the effects of land use change using image editing and Q sort method. Landscape and Urban Planning, 35, 213-230.

SWANWICK, C. (2002). Landscape Character Assessment: Guidance for England and Scotland. Countryside Agency, Cheltenham and Scottish Natural Heritage, Edinburgh.

TAHVANAINEN, L., TYRVAINEN, L., IHALAINEN, M., VUORELA, N. \& KOLEHMAINEN, O. (2001) Forest management and public perceptions: visual versus verbal information. Landscape and Urban Planning, 53, pp. 53-70.

WILLIS, K.G. \& GARROD, G.D. (1992) Assessing the value of future landscapes. Landscape and Urban Planning, 23, 17-32. 